Torta de Filtro, Resíduo da Indústria Sucroalcooleira - Uma Avaliação por Pirólise Lenta

\author{
Bernardino, C. A. R.; Mahler, C. F.; Veloso, M. C. C.; Romeiro, G. A.; \\ Schroeder, P.*
}

Rev. Virtual Quim., 2018, 10 (3), 551-573. Data de publicação na Web: 26 de junho de 2016

http://rvq.sbq.org.br

\title{
Filter Cake, Residue of the Sugarcane Industry - A Evaluation by Slow Pyrolysis
}

Abstract: Currently, the final destination of waste generated through urban, industrial, agricultural, and other activities has been a major concern in Brazil. The pyrolysis process is an excellent alternative for the treatment of agroindustrial residues such as filter cake. The objective of this paper was to evaluate a treatment by low pyrolysis of the filter cake residue of the sugarcane industry, aiming to obtain bioproducts with probable applications in the market. The results showed that the yield of the bioproducts were $68 \%$ biochar, $17 \%$ gas, $11 \%$ water and $4 \%$ bio-oil. In addition, the biochar generated was the bioproduct with the greatest potential of application, because it presented characteristics to be used as organic adsorbent and organic fertilizer.

Keywords: Filter cake; Pyrolysis; Biochar.

\section{Resumo}

Atualmente, há uma grande preocupação no Brasil com a destinação final dos resíduos gerados através das atividades urbanas, industriais, agrícolas, dentre outras. O processo de pirólise é uma excelente alternativa para o tratamento de resíduos agroindustriais como a torta de filtro. O objetivo deste trabalho foi avaliar um tratamento por pirólise lenta do resíduo torta de filtro da indústria sucroalcooleira, visando obter bioprodutos, com prováveis aplicações no mercado. Os resultados mostraram que o rendimento dos bioprodutos foram 68 \% de carvão, 17 \% de gás, 11 \% de água e $4 \%$ de óleo. Além disso, o carvão gerado foi o bioproduto com maior potencial de aplicação, pois apresentou características para ser utilizado como adsorvente orgânico e adubo orgânico.

Palavras-chave: Torta de filtro; Pirólise; Biocarvão.

\footnotetext{
* Universidade Federal Fluminense, Instituto de Química, Departamento de Química Orgânica, Campus do Valonguinho, CEP 24020-150, Niterói-RJ, Brasil.

$M$ priscilaschroeder@id.uff.br DOI: $\underline{10.21577 / 1984-6835.20180042}$
} 


\section{Torta de Filtro, Resíduo da Indústria Sucroalcooleira - Uma Avaliação por Pirólise Lenta}

\section{Cassiano A. R. Bernardino, ${ }^{a}$ Claudio F. Mahler, ${ }^{a}$ Márcia C. C. Veloso, ${ }^{b}$ Gilberto A. Romeiro, ${ }^{b}$ Priscila Schroeder ${ }^{\mathrm{b}, *}$}

${ }^{a}$ Universidade Federal do Rio de Janeiro, Programa de Pós-graduação em Engenharia Civil/Meio Ambiente - COPPE/UFRJ, Cidade Universitária, Ilha do Fundão, Rio de Janeiro.

' Universidade Federal Fluminense, Instituto Química, Departamento de Química Orgânica, Outeiro de São João Batista, S/N, Valonguinho, Centro, CEP 24020-141, Niterói-RJ, Brasil.

* priscilaschroeder@id.uff.br

Recebido em 12 de maio de 2018. Aceito para publicação em 6 de junho de 2018

\section{Introdução}

1.1. Resíduo da Agroindústria Sucroalcooleira - Torta de Filtro

1.2. Pirólise Lenta

\section{Materiais e Métodos}

2.1. Amostragem

2.2. Pirólise Branda

2.3. Caracterização da Torta de Filtro e do Biocarvão

2.4. Ensaios de Adsorção

\section{Resultados e Discussão}

3.1. Pirólise Lenta

3.2. Análise por Espectroscopia na Região do Infravermelho (FTIR) da Torta de Filtro e do Biocarvão

3.3. Composição Química da Torta de Filtro e do Biocarvão

3.4. Avaliação de Rendimento e Poder Calorífico no Processo de Pirólise

3.5. Perspectivas de Aplicações para o Biocarvão - Adubo Orgânico

3.6. Adsorção para Tratamento de Efluente

3.7. Isotermas de Adsorção

3.8. Cinética de Adsorção

\section{Considerações Finais}




\section{Introdução}

Atualmente, devido as sérias implicações para o meio ambiente, há uma grande preocupação no Brasil com a destinação dos resíduos sólidos, tais como: urbanos; da saúde; dos diversos setores industriais; agrícolas, entre outros. ${ }^{1}$

A maior parte dos resíduos gerados necessita de destinação adequada, e sua reintrodução na cadeia produtiva pode ser uma excelente solução. Uma das opções, que vem sendo bastante estudada para este fim, é o uso de tecnologias de conversão termoquímica para obtenção de produtos economicamente viáveis, como os biocombustíveis termoquímicos, que muitas vezes são produzidos regionalmente e podem contribuir para o equilíbrio econômico do país. ${ }^{2}$

Dentre estes processos termoquímicos, pode-se mencionar a Pirólise, que objetiva a obtenção de bioprodutos na forma líquida (bio-óleo e água pirolenhosa), sólida (biocarvão) e gás, que podem ser usados para diversas finalidades. As fontes de biomassas (agrícolas, florestais ou aquáticas) que podem ser utilizadas incluem casca de coco, bagaço de cana, sabugo de milho, pinhão manso, mamona, soja, borra de café, casca de licuri, casca de arroz, aparas florestais, aguapé, entre outras. ${ }^{3-7}$

O processo de pirólise é uma alternativa renovável e de fundamental importância para a destinação adequada de resíduos, podendo agregar valor aos bioprodutos, que podem ser aplicados como: biocombustíveis, insumos químicos, fertilizantes, antioxidante, remediação de solos, filtros, processos de adsorções e muitos outros segmentos. ${ }^{8-11}$

Neste trabalho será abordado um estudo de pirólise lenta do resíduo da torta de filtro, proveniente das indústrias sucroalcooleiras, com o objetivo de produzir, principalmente, biocarvão e verificar suas possíveis aplicações como bioadsorvente para corantes de efluentes industriais, adubo orgânico e combustível.

\subsection{Resíduo da Agroindústria Sucroalcooleira - Torta de Filtro}

O Brasil é o maior produtor de cana-deaçúcar (Saccharum officinarum L.) e além de ser exportador mundial de açúcar refinado, também utiliza o etanol como combustível de veículos. ${ }^{12}$

Dados da Companhia Nacional de Abastecimento (CONAB) revelaram uma expansão no mercado de açúcar e álcool na safra de 2017/2018 de 646 milhões de toneladas do total de cana moída, com diminuição de $1,7 \%$ em relação à safra 2016/2017, que foi de 657 milhões de toneladas. ${ }^{13}$ Para atender a esta expansão, mais áreas são plantadas e consequentemente, maiores quantidades de resíduos, como o bagaço de cana e a torta de filtro, são gerados.

A torta de filtro é um resíduo composto da mistura de bagaço moído e lodo da decantação, sendo proveniente do processo de clarificação do açúcar (Figura 1). ${ }^{14}$ 


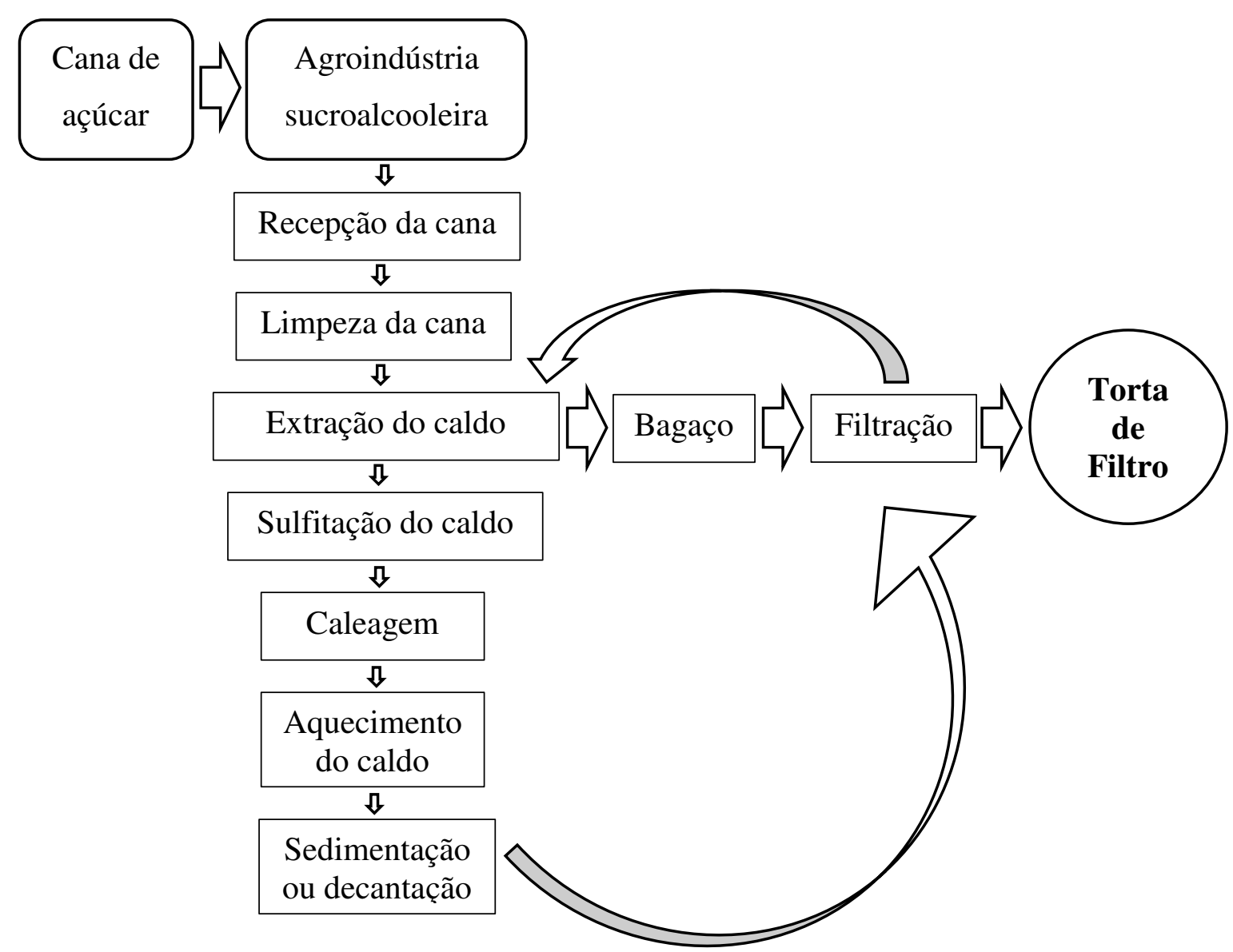

Figura 1. Geração da torta de filtro nas indústrias de açúcar e álcool

Neste processo, o caldo aquecido passa pela sulfitação e recebe uma solução de hidróxido de cálcio, favorecendo a elevação do $\mathrm{pH}$ e possibilitando a floculação das substâncias orgânicas coloidais. O caldo, clarificado e limpo, é evaporado para produzir o açúcar, e o lodo, formado pelos compostos insolúveis após um período de decantação, segue para filtração a vácuo, onde é recuperada a sacarose ainda existente. Ao lodo, mistura-se bagaço de cana finamente moído para permitir a consistência apropriada para a filtração a vácuo, que dá origem à torta de filtro. ${ }^{14}$

Cada tonelada de cana moída gera em torno de $40 \mathrm{~kg}$ de torta de filtro, resultando, segundo os dados da CONAB, em aproximadamente 26 milhões de toneladas. ${ }^{12,13}$

A maior parte da torta de filtro é constituída de matéria orgânica, em torno de $85,1 \%$, com composição média de $11 \%$ de lignina, $34 \%$ de hemicelulose e $38 \%$ de celulose e uma pequena fração mineral, constituída por fósforo, nitrogênio, cálcio, além de teores consideráveis de potássio, magnésio, enxofre, micronutrientes ( $\mathrm{Fe}, \mathrm{Mn}$, $\mathrm{Zn}, \mathrm{Cu}$ ) e baixas concentrações de metais pesados como: $\mathrm{Cr}, \mathrm{Cd}, \mathrm{Pb}$. A Tabela 1 mostra diferentes composições de tortas de filtro, em função das diferentes origens $d a$ produção da cana de açúcar. ${ }^{14-16}$ 
Tabela 1. Composição química da torta de filtro

\begin{tabular}{|c|c|c|c|c|}
\hline $\begin{array}{c}\text { Elemento } \\
\text { Químico }\end{array}$ & $\begin{array}{l}\text { Chacón et al } \\
\text { (2011) }\end{array}$ & $\begin{array}{l}\text { Santos et al } \\
\quad(2011)\end{array}$ & $\begin{array}{l}\text { Lima et al } \\
\text { (2009) }\end{array}$ & Unidade \\
\hline C & 358,9 & n.a. & 277,72 & g. $\mathrm{kg}^{-1}$ \\
\hline $\mathrm{N}$ & 17,30 & 9,50 & 18,70 & g. $\mathrm{kg}^{-1}$ \\
\hline$S$ & 3,40 & 7,20 & 3,48 & g. $\mathrm{kg}^{-1}$ \\
\hline$P$ & 19,1 & 3,30 & 9,62 & g.kg ${ }^{-1}$ \\
\hline $\mathrm{Mg}$ & 1,00 & 2,50 & 4,68 & g. $\mathrm{kg}^{-1}$ \\
\hline K & 1,60 & 4,60 & 117,11 & g. $\mathrm{kg}^{-1}$ \\
\hline $\mathrm{Ca}$ & 8,80 & 9,10 & 11,88 & g. $\mathrm{kg}^{-1}$ \\
\hline $\mathrm{Fe}$ & 11,86 & 23,8 & 0,17 & g. $\mathrm{kg}^{-1}$ \\
\hline $\mathrm{Cd}$ & 0,99 & n.a. & n.a. & $\mathrm{mg} \cdot \mathrm{kg}^{-1}$ \\
\hline $\mathrm{Mn}$ & 400,64 & 758 & n.a. & $\mathrm{mg} \cdot \mathrm{kg}^{-1}$ \\
\hline $\mathrm{Zn}$ & 81,14 & 282 & n.a. & $\mathrm{mg} \cdot \mathrm{kg}^{-1}$ \\
\hline $\mathrm{Cu}$ & 27,28 & 124 & n.a. & $\mathrm{mg} \cdot \mathrm{kg}^{-1}$ \\
\hline $\mathrm{Pb}$ & 4,06 & n.a. & n.a. & $\mathrm{mg} \cdot \mathrm{kg}^{-1}$ \\
\hline $\mathrm{Cr}$ & 19,06 & n.a. & n.a. & $\mathrm{mg} \cdot \mathrm{kg}^{-1}$ \\
\hline
\end{tabular}

n.a. - Não avaliado

Atualmente a torta de filtro é aplicada como adubo orgânico de maneira rotineira em áreas de plantio de cana nas dosagens de 80 a 100 toneladas por hectare. 0 ponto negativo deste resíduo é possibilidade do aumento da concentração de metais pesados no solo e da quantidade de nutrientes aplicados diretamente aos solos, que exigem o constante monitoramento dos ecossistemas agrícolas.

Resíduos orgânicos utilizados em quantidades acima do potencial do solo, ou das necessidades das culturas, podem causar problemas ambientais associados a perda de nitrogênio, ao aumento de patógenos e metais pesados, a acidificação ou salinização dos solos agrícolas e ainda podem promover a imobilização do nitrogênio, quando incorporado diretamente no solo, devido à estimulação da atividade microbiana nativa. ${ }^{17-19}$

A disponibilidade e o alto teor de matéria orgânica da torta de filtro mostra a potencialidade para o estudo de seu aproveitamento por pirólise lenta, na obtenção do biocarvão e suas diversas possibilidades de aplicação. 


\subsection{Pirólise Lenta}

A literatura relata várias definições para o processo de pirólise, uma degradação térmica de qualquer material orgânico na ausência de oxigênio, ou em concentrações menores que a necessária para uma combustão que varia basicamente na faixa de temperatura envolvida no processo. ${ }^{20}$ Nestes processos de pirólise, a biomassa é aquecida a temperaturas que variam de $400^{\circ} \mathrm{C}$ até o de gaseificação que é de $1000^{\circ} \mathrm{C}$. ${ }^{21}$

O processo de conversão térmica, denominado pirólise lenta ou conversão a baixa temperatura (CBT), teve avanços significativos na década de 80 pelos pesquisadores Bayer e Kutubuddin. ${ }^{22} \mathrm{O}$ processo consiste em aquecer o material, previamente seco, a temperatura de 380 420 으, em atmosfera livre de oxigênio, por um período médio de 2 a 3 horas. Os bioprodutos obtidos apresentam rendimentos variando em função da composição dos resíduos. ${ }^{3,5,22-25}$

A composição química do bio-óleo e a qualidade do biocarvão são funções da origem do resíduo usado como matéria prima. A medida do poder calorífico é determinante na avaliação para aplicação destes, nas suas formas brutas, como biocombustivéis. ${ }^{23} \mathrm{~A}$ maior aplicação do bio-óleo é como combustível. ${ }^{24,26,27}$ Já o biocarvão pode ser utilizado como combustível sólido, na recomposição de solos agrícolas, no sequestro de carbono, no tratamento de efluentes como adsorvente, na remediação de solos e de águas. ${ }^{8,9}$

\section{Materiais e Métodos}

\subsection{Amostragem}

A torta de filtro, proveniente da indústria sucroalcooleira, utilizada neste trabalho, foi doada pela Cooperativa Agroindustrial do
Estado do Rio de Janeiro (COAGRO), localizada em Campos Goytacazes - RJ, com

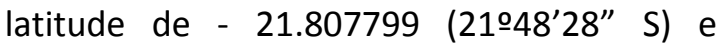
longitude de -41.272371 (4116'20" W). A torta estava em empilhada em um monte, e as sub-amostras foram coletadas a partir de diferentes pontos da pilha, com auxílio de uma pá metálica, e depois homogeneizadas, utilizando-se luvas descartáveis, formando uma amostra composta. As amostras (10 kg cada) foram acondicionadas em sacos de polietileno e transportadas para o laboratório.

\subsection{Pirólise Branda}

A torta de filtro foi seca em estufa a 105응 \pm 2 으, baseado na norma NBR- 8293/1983. Em seguida, $200 \mathrm{~g}$ da torta de filtro seca foram submetidos ao tratamento por pirólise branda. As condições utilizadas para o processo de pirólise foram atmosfera inerte $\operatorname{com} \mathrm{N}_{2}$, temperatura de $380 \stackrel{\circ}{\circ}$, com uma taxa de aquecimento de $15^{\circ} \mathrm{C} \mathrm{min}^{-1}$ e tempo de residência de 2 horas.

Os ensaios de conversão por pirólise foram realizados em um reator de bancada consistindo de um forno de marca Heraeus R/O 100, um controlador de temperatura, suprimento de nitrogênio, um leito fixo constituído de vidro tipo boro-silicato com juntas esmerilhadas, de dimensões $1,40 \mathrm{~cm} x$ $10 \mathrm{~mm}$, um sistema de coleta de líquidos formado por um condensador, um funil de decantação $(500 \mathrm{~mL})$ e três frascos lavadores de gases (Figura 2).

A conversão inicia-se a temperatura de 380 ㄷ. Os produtos de conversão, em fase gasosa, são impelidos para a região de condensação, com refrigeração na faixa de 5 15 ㅇ. . A fase não condensada, é coletada em um sistema de lavagem de gases, constituído por dois frascos lavadores contendo solução de $\mathrm{NaOH} 10 \%(\mathrm{~m} / \mathrm{v})$ e solução de $\mathrm{HCl} 10 \%$ (v/v). A fase condensável, constituída de duas frações, aquosa (água de pirólise) e orgânica (bio-óleo), foi coletada em um funil de 
separação e isolada por diferença de biocarvão que após resfriamento foi densidade. Restando apenas no conversor o removido e analisado.

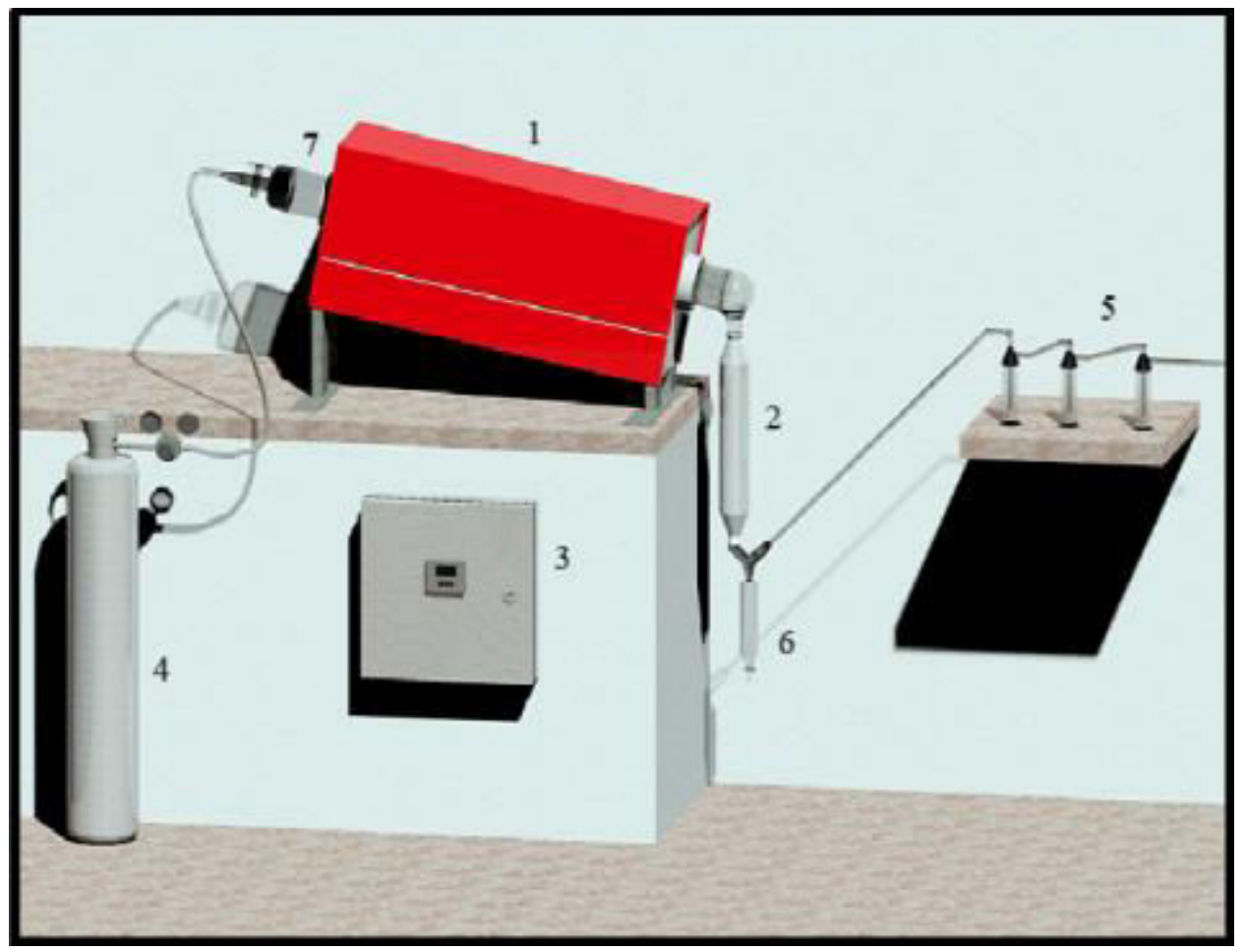

Figura 2. Esquema do reator termoelétrico modo batelada de conversão à baixa temperatura: (1) reator pirolítico; (2) condensador; (3) controlador de temperatura; (4) cilindro de nitrogênio; (5) frascos lavadores de gases; (6) coletor de fração líquida; (7) leito de borosilicato (LABCON - IQ/UFF)

\subsection{Caracterização da Torta de Filtro e do Biocarvão}

Foram realizadas as seguintes análises para a torta de filtro e o biocarvão:

$\checkmark$ Espectroscopia na região do Infravermelho (FTIR);

$\checkmark$ Análise elementar $(\mathrm{C}, \mathrm{H}, \mathrm{N}, \mathrm{S})$;

$\checkmark$ Teor de metais $(\mathrm{K}, \mathrm{Mg}, \mathrm{Ca}, \mathrm{Fe}, \mathrm{Cd}, \mathrm{Cr}$, $\mathrm{Mn}, \mathrm{Cu}, \mathrm{Zn}, \mathrm{Pb})$;

$\checkmark \quad$ Teor de fósforo

\subsection{Ensaios de Adsorção}

Foram realizadas as análises de microscopia eletrônica de varredura (MEV), área superficial específica e porosidade do biocarvão antes do processo de adsorção para verificar sua qualidade e potencialidade na remoção de corantes orgânicos.

Em seguida, para os ensaios de adsorção na fase líquida foi utilizado como adsorbato o reagente azul de metileno, marca Merck (Fórmula Molecular: $\mathrm{C}_{16} \mathrm{H}_{18} \mathrm{ClN}_{3} \mathrm{~S}$ - Massa Molecular: $319,5 \mathrm{~g} \mathrm{~mol}^{-1}$ ).

Para este ensaio foram preparadas as seguintes soluções aquosas de azul de metileno:

a) Solução estoque de $250 \mathrm{mg} \mathrm{L}^{-1}$

b) Solução de trabalho $(0,5 ; 1,0 ; 2,5$; 5,$0 ; 7,5 ; 10,0 ; 12,5 ; 15,0 ; 17,5 \mathrm{mg} \mathrm{L}^{-1}$ ) 
As análises foram feitas no espectrofotômetro UV/VIS Varian Cary 50 Conc, em $\lambda=665 \mathrm{~nm}$.

Para os ensaios de adsorção, foram utilizados $10 \mathrm{mg}$ de biocarvão, com granulometria de até 0,045 $\mathrm{mm}$ (MESH/TYLER 325), colocados em contato com $10 \mathrm{~mL}$ de soluções aquosas de azul de metileno $(\mathrm{pH}=6,2)$ em várias concentrações $(0,5 ; 1,0 ; 2,5 ; 5,0 ; 7,5 ; 10,0 ; 12,5 ; 15,0 ; 17,5$ $\mathrm{mg} \mathrm{L}^{-1}$ ) por uma $1 \mathrm{~h}$, com agitação constante em placa de agitação magnética, à temperatura ambiente $(25 \stackrel{\circ}{\circ})$. A isoterma de adsorção foi construída como mostrado na equação 1.

$$
q_{e}=\frac{\left(C_{0}-C_{e}\right) V}{m} \quad \text { Eq. } 1
$$

Os dados da isoterma foram interpretados pelos modelos de Langmuir e Freundlich.

Os ensaios cinéticos de adsorção foram utilizados $10 \mathrm{mg}$ de carvão juntamente com
$10 \mathrm{~mL}$ de soluções aquosas de azul de metileno ( $\mathrm{pH} \mathrm{6,2),} \mathrm{com} \mathrm{concentração} \mathrm{de} 10$ $\mathrm{mg} \mathrm{L}^{-1}$. Com variação do tempo de $15,30,60$, 120 e 180 min e agitação constante em placa magnética, com temperatura ambiente (25 oC). A interpretação dos dados foi realizada pelos modelos cinéticos pseudo $1 \underline{a}$ ordem e pseudo 2a ordem.

\section{Resultados e Discussão}

\subsection{Pirólise Lenta}

Os experimentos de pirólise da torta de filtro, realizados nas condições: fluxo constante de nitrogênio $\left(0,5 \mathrm{~L} \mathrm{~min}^{-1}\right)$; taxa de aquecimento de $15 \stackrel{\circ}{ } \mathrm{C} \mathrm{min}^{-1}$; temperatura de $380^{\circ} \mathrm{C}$ e tempo de residência do material no reator de $2 \mathrm{~h}$ levaram a quatro frações: bioóleo, biocarvão, fração aquosa e gás, com os rendimentos médios das conversões descritos na Figura 3.

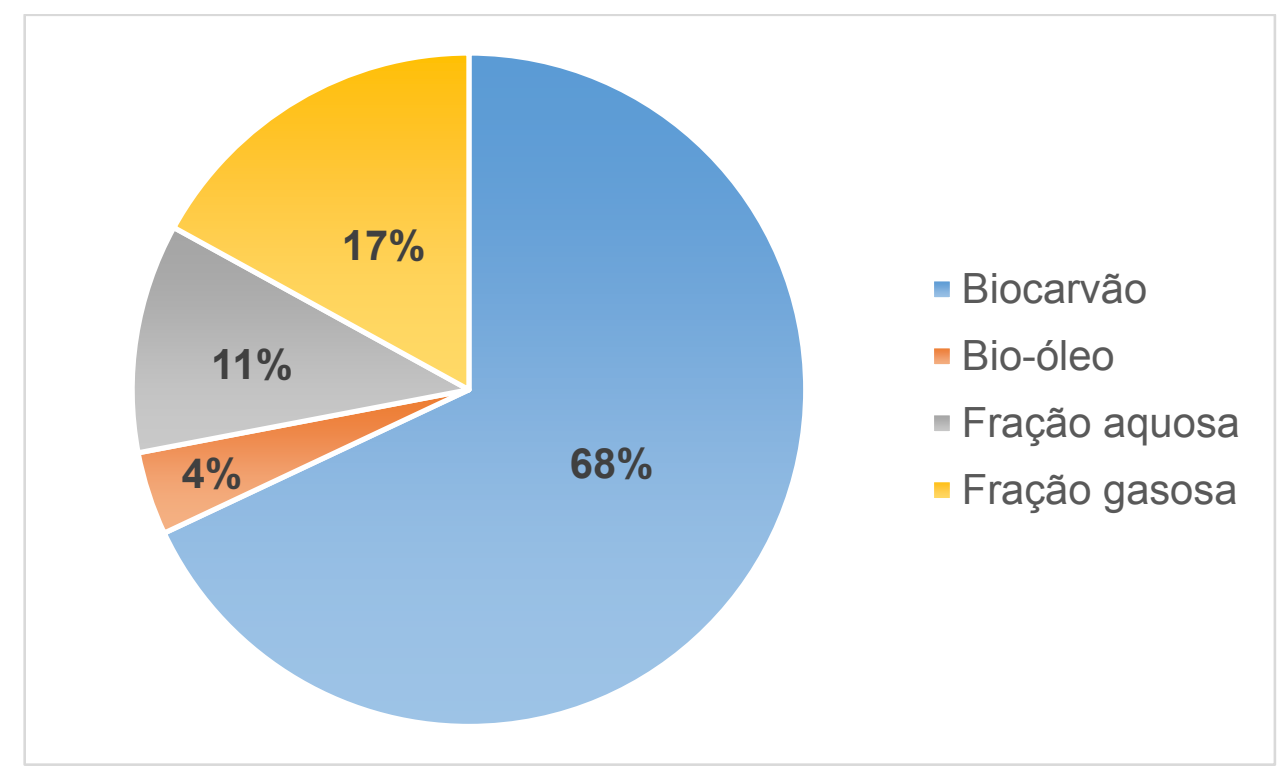

Figura 3. Rendimento médio dos produtos obtidos por pirólise lenta da torta de filtro (Atmosfera de $\mathrm{N}_{2} ; \mathrm{T}-380^{\circ} \mathrm{C} ; \mathrm{t}-2 \mathrm{~h}$ )

O rendimento da fração gasosa foi bastante promissor e poderá suprir as necessidades do processo no aquecimento do reator de pirólise. A fração aquosa pode ser usada na cadeia produtiva sucroalcooleira, como fertilizante no plantio 
da cana de açúcar, e o bio-óleo pode ser utilizado como combustível na geração de energia do próprio processo de pirólise. Observa-se um rendimento da fração sólida, o biocarvão, bastante elevado (68\%) o que justifica investimentos na produção deste produto que poderá vir a ter potencial em diversas aplicações. Neste trabalho estudamos suas características químicas e físico-químicas, bem como, sua potencialidade como combustível, adubo orgânico e adsorvente orgânico.

\subsection{Análise por Espectroscopia na Região} do Infravermelho (FTIR) da Torta de Filtro e do Biocarvão

O perfil das absorções do resíduo da torta de filtro seco e o carvão pirolítico foram comparados por Espectroscopia na Região do Infravermelho (FTIR). Os espectros de Infravermelho da torta de filtro (Figura 4) e do biocarvão (Figura 5) mostraram absorções bastante semelhantes, porém, com as intensidades dos sinais diferentes.

Observa-se que houve uma considerável redução na intensidade de absorção no espectro de Infravermelho na região de 3400 $\mathrm{cm}^{-1}$ relativas às deformações axiais da ligação $\mathrm{OH}$ e da ligação $\mathrm{NH}_{2}$ no carvão pirolítico e o desaparecimento da carbonila na região de $1647 \mathrm{~cm}^{-1}$, da torta de filtro em relação ao biocarvão, demonstrando a diminuição de açúcares (celulose e hemicelulose) com o processo de pirólise.

A comparação dos perfis de Infravermelho, Figuras 4 e 5, revelam dados importantes em relação a grupos funcionais encontrados na lignina, celulose, hemicelulose e extrativos, composição antes da conversão. Os grupos $\mathrm{OH}$ e $\mathrm{NH}_{2}$ quando submetidos a temperatura de 380 oC são envolvidos em mecanismos de termodecomposição em fase gasosa com a perda de $\mathrm{H}_{2} \mathrm{O}$ e $\mathrm{NH}_{3}$, diminuindo as absorções na região de $3400 \mathrm{~cm}^{-1}$

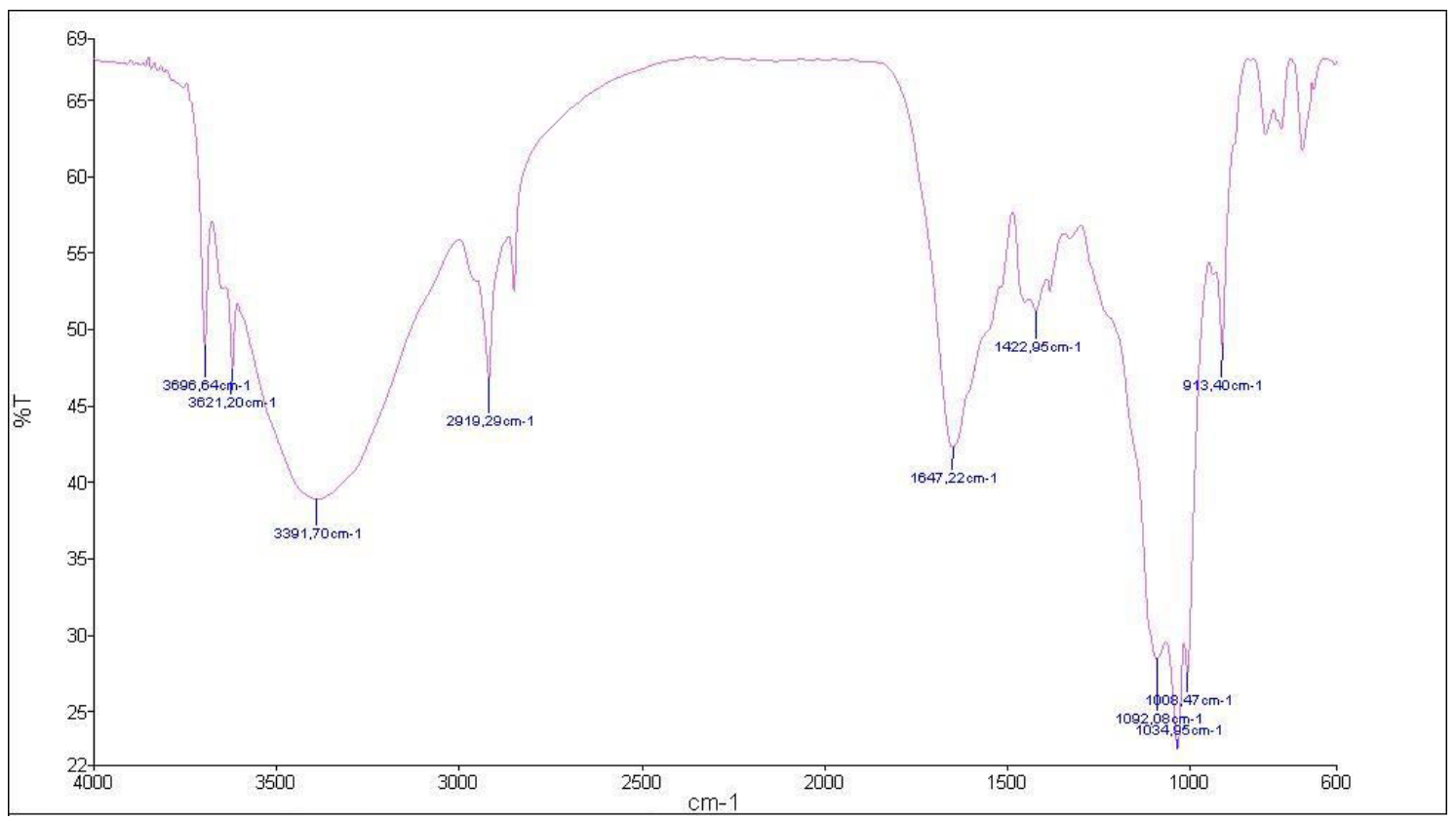

Figura 4. Espectro na região do Infravermelho da amostra de torta de filtro 


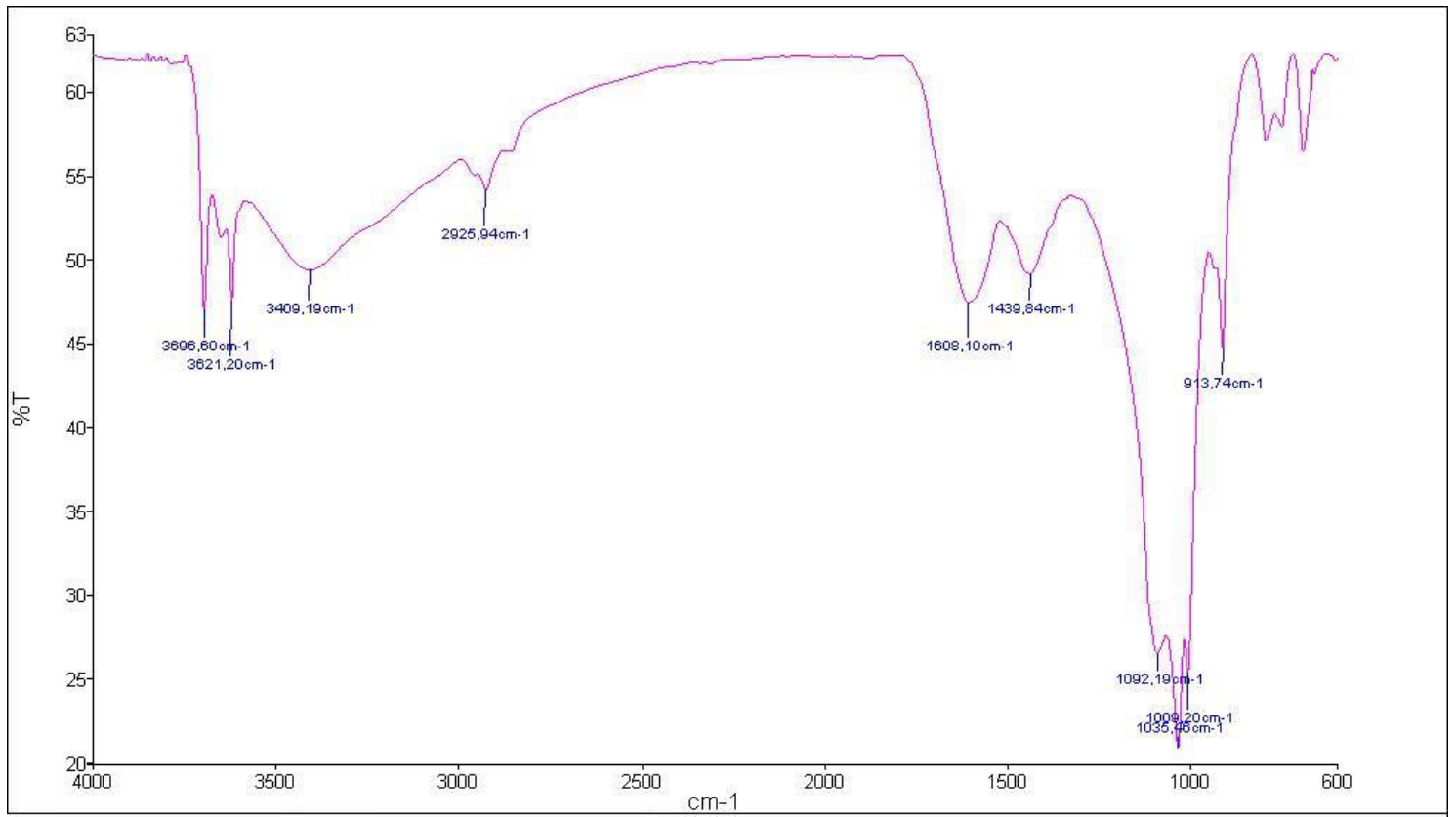

Figura 5. Espectro na região do Infravermelho do biocarvão

\subsection{Composição Química da Torta de} Filtro e do Biocarvão

Os teores de $\mathrm{C}, \mathrm{H}, \mathrm{N}$ e $\mathrm{S}$, foram analisados utilizando-se o analisador Elementar marca ELEMENTAR Vario Micro CHNS e as análises para os metais $\mathrm{K}, \mathrm{Mg}, \mathrm{Ca}, \mathrm{Fe}, \mathrm{Cd}, \mathrm{Cr}, \mathrm{Mn}, \mathrm{Cu}$, $\mathrm{Zn}, \mathrm{Pb}$, bem como o teor de $\mathrm{P}$, foram realizadas pela técnica de Espectrometria de Absorção Atômica (Tabela 2).

O biocarvão proveniente da pirólise da torta de filtro apresenta um aumento no teor de carbono e, um pequeno aumento no teor de $\mathrm{N}, \mathrm{P}, \mathrm{K}, \mathrm{Ca}, \mathrm{Mg}, \mathrm{Fe}$, e não se observa a presença de metais pesados em relação à torta de filtro. A Agência Nacional de Energia Elétrica (ANEEL) considera que a turfa constitui um dos primeiros estágios do carvão, com baixo teor de carbono na ordem de 45\%; o linhito apresenta um índice que varia de $60 \%$ a $75 \%$; o carvão betuminoso (hulha), mais utilizado como combustível contém cerca de $80 \%$ de carbono, e o mais puro dos carvões; o antracito apresenta um conteúdo carbonífero superior a $90 \%{ }^{28}$ Embora este biocarvão apresente baixo teor de C (25,44\%), estes resultados são promissores para a utilização deste por não poluir solos e mananciais hídricos por metais.

Tabela 2. Composição química da torta de filtro e do biocarvão obtido por pirólise $(n=3)$

\begin{tabular}{ccc}
\hline Elemento Químico & Torta de Filtro (\%) & Biocarvão (\%) \\
\hline C & $24,66 \pm 1,94$ & $25,44 \pm 1,70$ \\
N & $2,33 \pm 0,20$ & $2,04 \pm 0,15$ \\
H & $3,64 \pm 0,27$ & $2,33 \pm 0,14$ \\
S & $0,80 \pm 0,04$ & $0,81 \pm 0,07$ \\
\hline
\end{tabular}




\begin{tabular}{crr}
\hline $\mathrm{P}$ & $1,04 \pm 0,01$ & $1,23 \pm 0,16$ \\
$\mathrm{Kg}$ & $0,51 \pm 0,01$ & $0,72 \pm 0,04$ \\
$\mathrm{Ca}$ & $0,54 \pm 0,05$ & $0,69 \pm 0,07$ \\
$\mathrm{Fe}$ & $1,78 \pm 0,01$ & $2,45 \pm 0,04$ \\
$\mathrm{Cd}$ & $1,19 \pm 0,09$ & $1,79 \pm 0,08$ \\
$\mathrm{Mn}$ & $\sim 0,00$ & $\sim 0,00$ \\
$\mathrm{Zn}$ & $0,10 \pm 0,00$ & $0,14 \pm 0,01$ \\
$\mathrm{Cu}$ & $0,01 \pm 0,00$ & $0,02 \pm 0,00$ \\
$\mathrm{~Pb}$ & $0,01 \pm 0,00$ & $0,01 \pm 0,00$ \\
$\mathrm{Cr}$ & $\sim 0,00$ & $\sim 0,00$ \\
\hline $\mathrm{O}$ " " representa valores aproximados de $0,00 \%$ & $\sim 0,00$ \\
\hline
\end{tabular}

3.4. Avaliação de Rendimento e Poder Calorífico no Processo de Pirólise

Na Tabela 3 é feita uma comparação entre o poder calorífico superior (PCS) da torta de filtro seca e de seus produtos obtidos na conversão por pirólise lenta.

A Tabela 4 mostra o balanço de massa do processo por pirólise lenta, considerando a massa inicial da torta de filtro seca de 0,200 kg. É importante salientar, que para se obter uma tonelada de torta de filtro seca, são necessárias 1,83 toneladas do resíduo úmido, devido ao teor de umidade ser $54,57 \%$.

Com os valores apresentados, pode-se calcular a quantidade de energia para uma tonelada de torta de filtro, como observado na Tabela 5.

Tabela 3. Poder Calorífico dos produtos por pirólise lenta

\begin{tabular}{cccccc}
\hline Parâmetro & Torta de Filtro & Bio-óleo & Biocarvão & Gás & Fração Aquosa \\
\hline $\begin{array}{c}\text { Rendimentos (\%) } \\
\begin{array}{c}\text { PCS } \\
\left(\mathrm{MJ} \mathrm{kg}^{-1}\right)\end{array}\end{array}$ & 100 & 4 & 68 & 17 & 11 \\
\hline
\end{tabular}

Tabela 4. Avaliação do rendimento do processo por pirólise lenta $(\mathrm{kg})$

\begin{tabular}{ccccc}
\hline Torta de Filtro Seca & Bio-óleo & Biocarvão & Gás & Fração Aquosa \\
\hline 0,200 & 0,008 & 0,136 & 0,034 & 0,022 \\
1000 & 40 & 680 & 170 & 110 \\
\hline
\end{tabular}


Tabela 5. Avaliação do poder calorífico superior para o processo de pirólise lenta

\begin{tabular}{cccc}
\hline & $\begin{array}{c}\text { PCS } \\
\left(\mathbf{M J ~ k g}^{-1}\right)\end{array}$ & Massa $(\mathbf{k g})$ & $\begin{array}{c}\text { Energia produzida (MJ) a } \\
\text { partir de 1 kg da Torta de } \\
\text { Filtro seca }\end{array}$ \\
\hline Torta de Filtro (seca) & 7,72 & 1,00 & 7,72 \\
Bio-óleo & 26,46 & 0,04 & 1,058 \\
Biocarvão & 8,78 & 0,68 & 5,970 \\
Gás & 4,07 & 0,17 & 0,692 \\
\hline
\end{tabular}

É importante ressaltar que a estimativa de geração total do resíduo da torta de filtro foi de aproximadamente 26 milhões de toneladas na safra de 2017/2018, no Brasil. ${ }^{29}$ Teoricamente a potencialidade deste resíduo no tratamento por pirólise lenta é de aproximadamente 14 milhões de toneladas de torta de filtro seca por ano, devido ao teor de umidade ser de $54,57 \%$.

A estimativa total dos seus respectivos bioprodutos são: 0,52 milhões toneladas de bio-óleo; 8,8 milhões de toneladas de biocarvão; 2,2 milhões de toneladas de gás e 1430 milhões de toneladas de fração aquosa. Sendo assim a energia estimada para o processo por pirólise branda seria aproximadamente de $13759.10^{6} \mathrm{MJ}$ de bioóleo, $77264.10^{6} \mathrm{MJ}$ de carvão e $8954.10^{6} \mathrm{MJ}$ de gás.

\subsection{Perspectivas de Aplicações para o Biocarvão - Adubo Orgânico}

O desenvolvimento de processos que permitam transformar resíduos agrícolas em carvão pirolítico com características apropriadas para o uso como condicionantes do solo e adubos orgânicos, não só é altamente desejável como também estratégico para a agroindústria. Um carvão pirolítico com tais características pode agregar valor ao carvão vegetal, tanto por criar um uso inovador, quanto por ser objeto de captação de recursos destinados ao mecanismo de desenvolvimento limpo. ${ }^{30}$

$\mathrm{O} \mathrm{C}, \mathrm{H}$ e O são essenciais para os tecidos vegetais, constituindo cerca de $90 \%$ da matéria seca de uma planta. ${ }^{31}$ Portanto, as plantas necessitam de água $\left(\mathrm{H}_{2} \mathrm{O}\right)$ e de diferentes moléculas orgânicas para sua sobrevivência. Esses elementos são obtidos pelas plantas a partir da água absorvida pelas raízes e do $\mathrm{CO}_{2}$ absorvido via fotossíntese. Os macronutrientes como o $\mathrm{N}, \mathrm{P}, \mathrm{K}$ são de grande importância devido as grandes quantidades absorvidas pelas plantas. $\mathrm{O} N$ geralmente encontrando-se em concentrações que variam de 1 a $5 \%$ da matéria seca. A concentração de $P$ pode variar de 0,10 a $1,0 \%$ da matéria seca, e o $\mathrm{K}$ encontra-se na faixa de 1,0 a $3,5 \%{ }^{32} \mathrm{~A}$ falta desses elementos nos solos pode acarretar no atraso do desenvolvimento das plantas e do florescimento, na queda prematura das folhas, e na diminuição da frutificação. ${ }^{33} \mathrm{~A}$ Tabela 6 mostra a concentração média de elementos essenciais da matéria seca de um vegetal e as variações das concentrações mínimas e máximas encontradas no biocarvão. ${ }^{32}$ 
Tabela 6. Comparação entre a concentração média de elementos essenciais da matéria seca de um vegetal com as variações das concentrações mínimas e máximas encontradas no biocarvão. ${ }^{32}$

\begin{tabular}{ccc}
\hline Elemento químico & Concentrações (\%) & Biocarvão da torta de filtro (\%) \\
\hline C & 42 & $23,60-27,39$ \\
H & $2,0-3,5$ & $1,81-2,21$ \\
S & 6 & $2,14-2,54$ \\
O & $0,2-0,3$ & $0,73-0,94$ \\
$P$ & 44 & $59,51-65,07$ \\
$\mathrm{Mg}$ & $0,12-0,22$ & $1,05-1,36$ \\
$\mathrm{~K}$ & $0,2-0,4$ & $0,70-0,76$ \\
$\mathrm{Ca}$ & $1,5-3,0$ & $0,65-0,76$ \\
$\mathrm{Fe}$ & $1,0-2,0$ & $2,40-2,48$ \\
$\mathrm{Mn}$ & $0,5-1,5$ & $1,70-1,87$ \\
$\mathrm{Zn}$ & $0,5-1,5$ & $0,14-0,15$ \\
$\mathrm{Cu}$ & $0,5-1,5$ & $0,008-0,010$ \\
\hline & $0,5-1,5$ & 0,022 \\
\hline
\end{tabular}

Analisando a composição química do biocarvão proveniente da torta de filtro em comparação a composição de matéria seca, observa-se que este tem uma boa perspectiva para ser utilizado como adubo orgânico em solos agrícolas, pois apresenta quantidades adequadas de $\mathrm{N}, \mathrm{P}$ e $\mathrm{K} .{ }^{32}$ Além disso, o biocarvão pode apresentar características que aumentam a capacidade de retenção de água e nutrientes no solo devido à sua natureza porosa e forma relativamente estável da matéria orgânica, e promove também a absorção de substâncias orgânicas solúveis. ${ }^{34}$

\subsection{Adsorção para Tratamento de} Efluente

A remoção de corantes sintéticos presentes em efluentes industriais é de grande interesse, uma vez que alguns desses corantes e seus produtos de degradação podem ser carcinogênicos e tóxicos e, consequentemente, o seu tratamento não pode depender somente da biodegradação. ${ }^{35}$

A utilização de resíduos agroindustriais, transformados em carvão pirolítico é uma alternativa para desenvolver adsorventes de baixo custo, contribuindo para a redução dos custos na eliminação dos resíduos agrícolas. ${ }^{36}$ 
A capacidade do carvão de pirólise em adsorver substâncias orgânicas é dependente de vários fatores, como: granulometria, área superficial, densidade, $\mathrm{pH}$, teor de cinzas, estrutura interna dos poros, presença de grupos funcionais na superfície dos poros que conferem alta reatividade da superfície, dimensões dos poros e alta resistência mecânica. ${ }^{37,38}$

Os materiais carbonosos ativados $\mathrm{e}$ pirolíticos são sólidos porosos com grande capacidade de adsorção. Em geral, estes materiais ativados possuem alta área superficial (300 a $2500 \mathrm{~m}^{2} \mathrm{~g}^{-1}$ ) e grande volume de poros acessíveis a gases. Já para os carvões de pirólise a literatura relata baixas e médias áreas superficiais $\left(0\right.$ a $490 \mathrm{~m}^{2}$ $\left.\mathrm{g}^{-1}\right)$, porém apresentam altas taxas de adsorções para corantes de moléculas grandes. ${ }^{8,37,38}$

Na Figura 6 verifica-se a isoterma de adsorção/dessorção de $\mathrm{N}_{2}$ a $77 \mathrm{~K}$ que fornece informações qualitativas preliminares sobre o mecanismo de adsorção e da estrutura porosa do biocarvão da torta de filtro. De acordo com a classificação BET, observa-se que a isoterma é característica de formação de sólidos mesoporosos e macroporosos. A área superficial determinada pelo método BET foi de $19,7856 \mathrm{~m}^{2} \mathrm{~g}^{-1}$, uma área específica superficial baixa, porém eficiente para remoção de efluentes que apresentem moléculas orgânicas grandes.

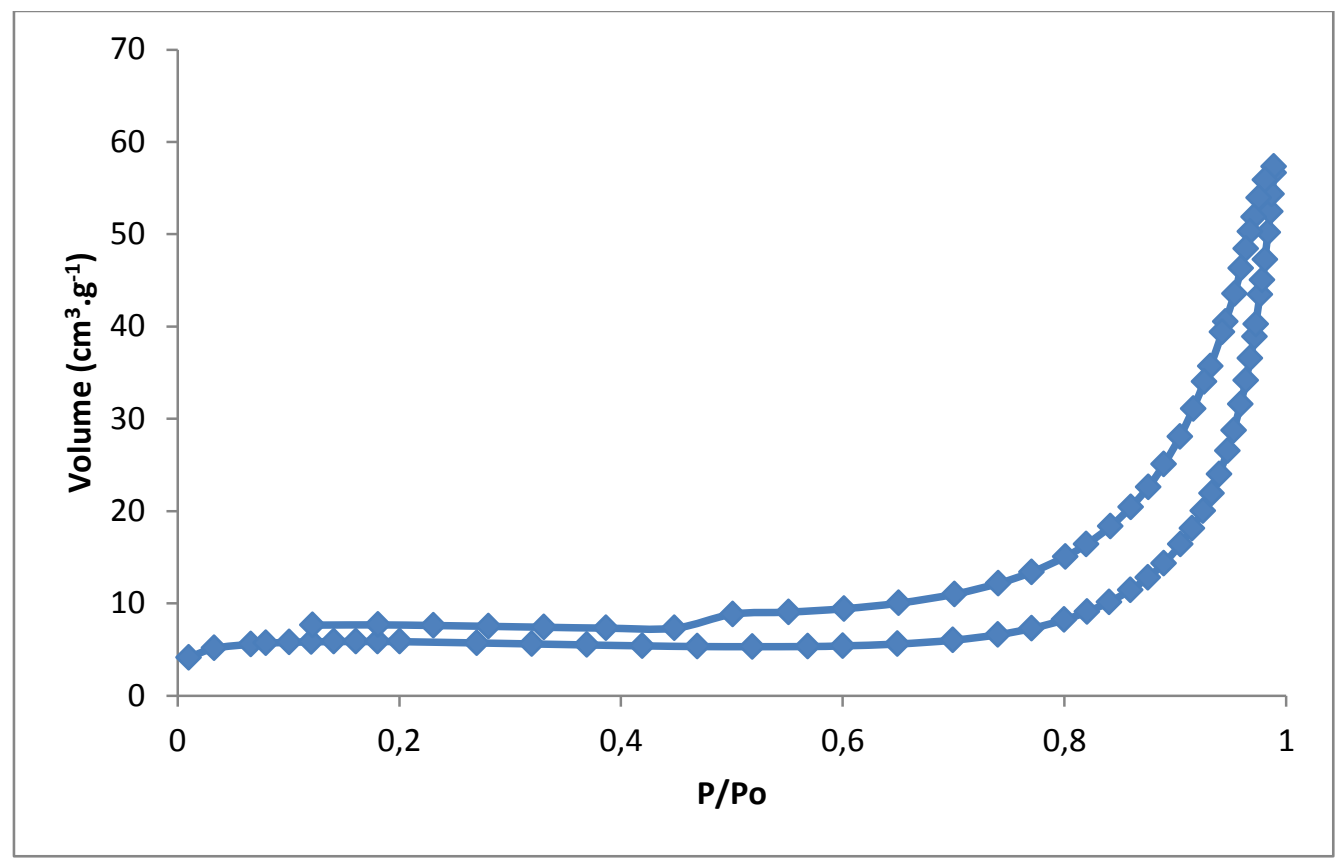

Figura 6. Isoterma de adsorção/dessorção de $\mathrm{N}_{2}$ a $77 \mathrm{~K}$ para o biocarvão

A distribuição do diâmetro de poros é mostrada na Figura 7, segundo as classes: microporos $\varnothing<20 \AA$, mesoporos $20 \AA<\varnothing<$ $500 \AA$ e macroporos $\varnothing>500 \AA$. A análise da distribuição do volume de poros em função do diâmetro indicou que o biocarvão proveniente da torta de filtro é principalmente constituído de mesoporos com diâmetro entre $20 \AA ̊$ e $500 \AA ̊$.
A micrografia obtida por MEV do biocarvão (Figura 8) demonstra uma superfície porosa formada pela intensa eliminação de voláteis e gases, resultado que pode ser atribuído à presença de material mineral, que causa uma maior desintegração nas partículas do biocarvão. ${ }^{39}$ 


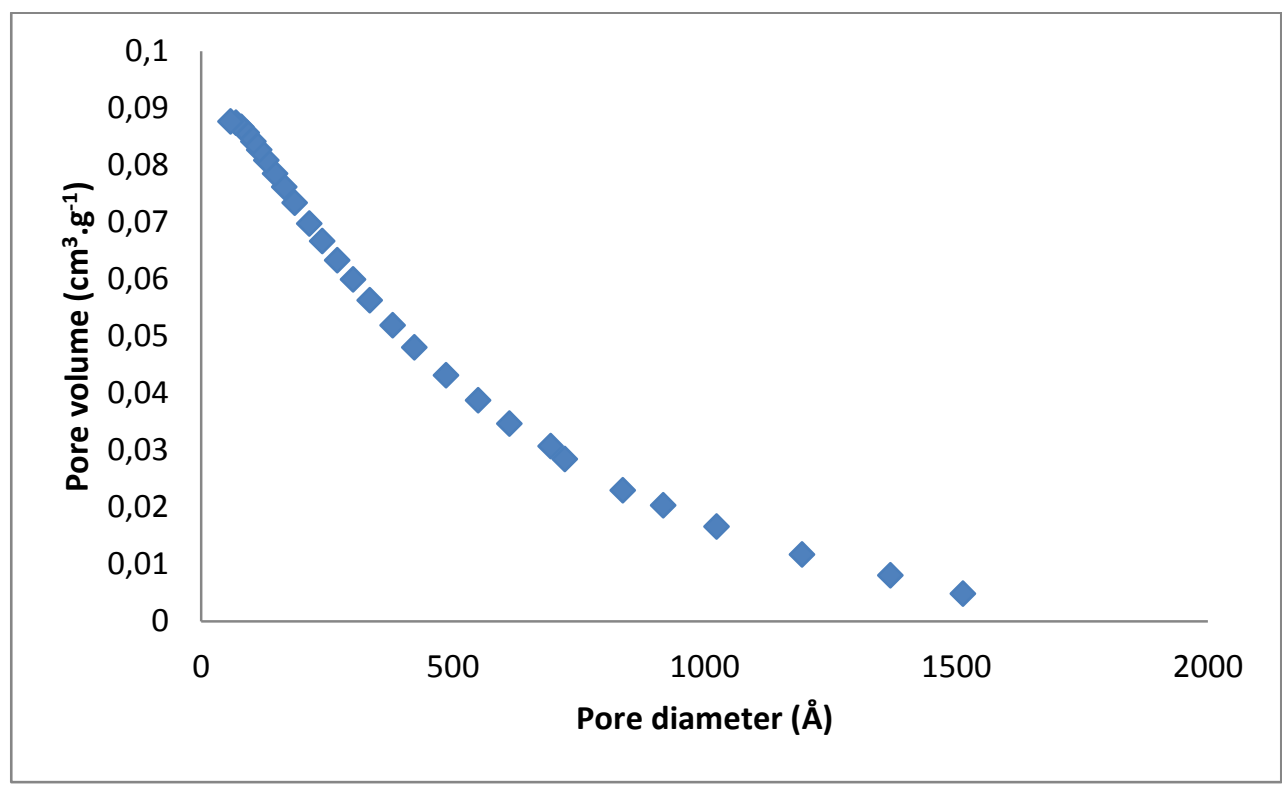

Figura 7. Distribuição do diâmetro de poros para o biocarvão

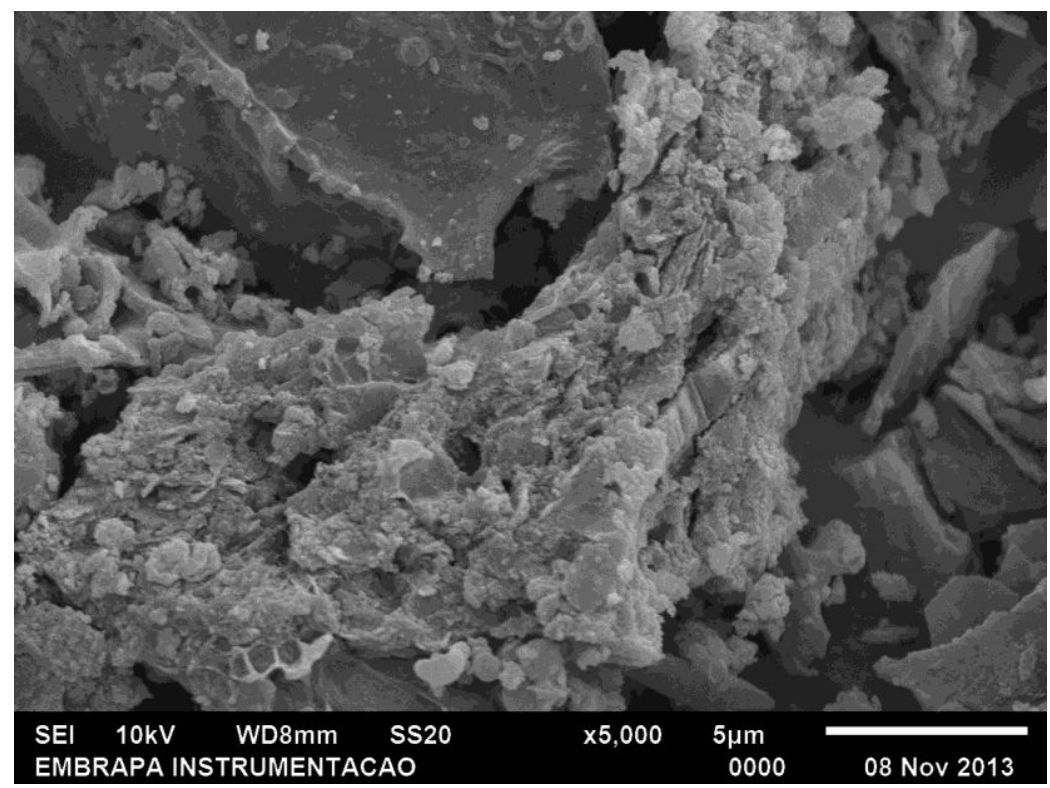

Figura 8. Micrografia obtida por MEV do biocarvão da torta de filtro

\subsection{Isotermas de Adsorção}

Na Figura 9 observa-se a isoterma de adsorção do azul de metileno pelo biocarvão (10 mg), a partir de soluções aquosas de 10 $\mathrm{mL}$ com diferentes concentrações $(0,5 ; 1,0$; 2,$\left.5 ; 5,0 ; 7,5 ; 10 ; 12,5 ; 15,0 ; 17,5 \mathrm{mg} \cdot \mathrm{L}^{-1}\right)$, com temperatura de $25 \stackrel{\circ}{\circ}$ e pH de 6,2 .
O gráfico representado pela quantidade de azul de metileno adsorvido no equilíbrio $\left(q_{\mathrm{e}}\right)$ vs concentrações de equilíbrio $\left(C_{e}\right)$, mostra uma tendência de uma quantidade de adsorção máxima, para esses dados. Por este motivo, os dados foram processados pelo modelo de Langmuir e Freundlich. 


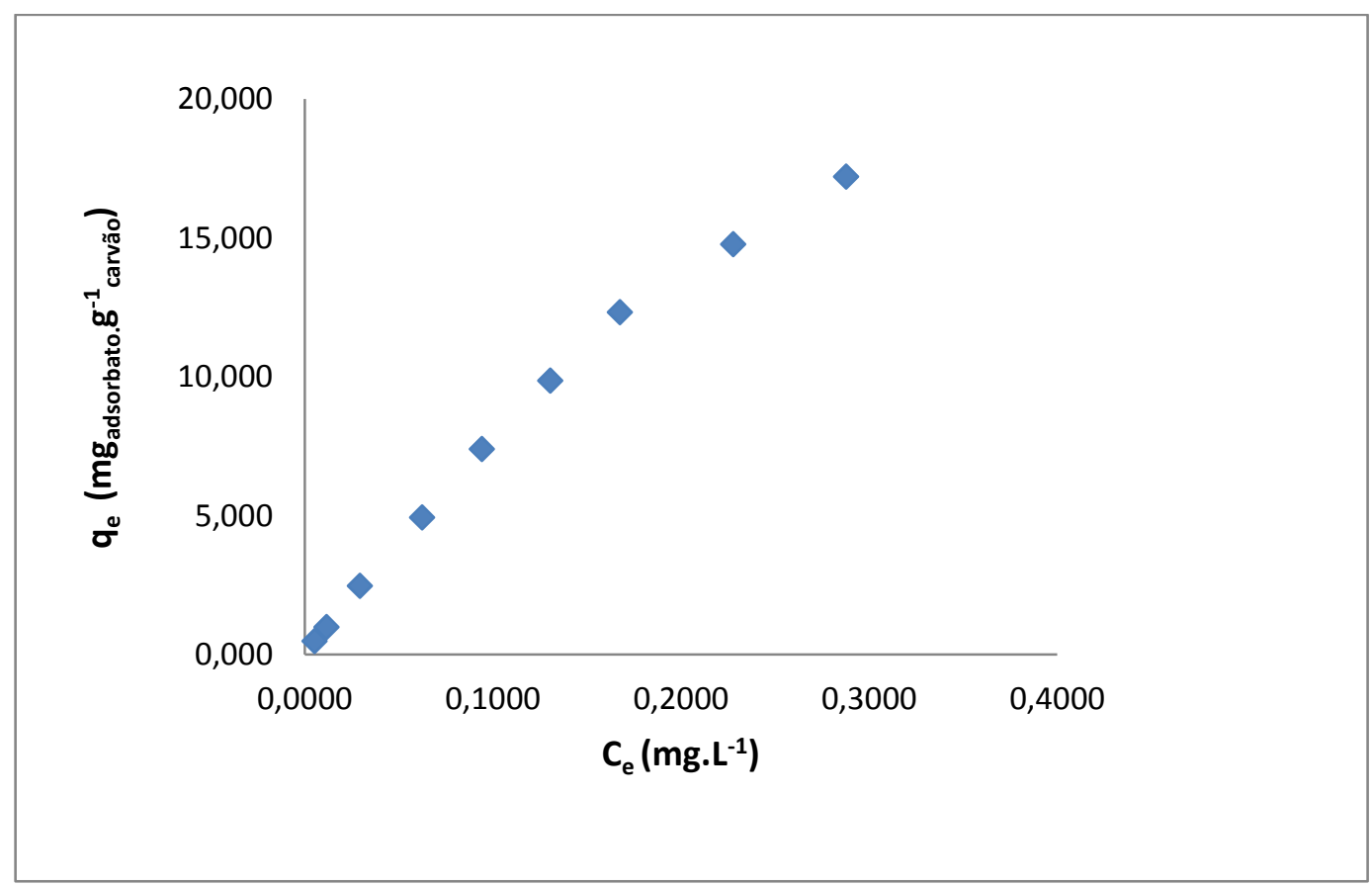

Figura 9. Isoterma de adsorção do azul de metileno em carvão pirolítico; $10 \mathrm{~mL}$ de soluções aquosas de azul de metileno, a 0,$5 ; 1,0 ; 2,5 ; 5,0 ; 7,5 ; 10 ; 12,5 ; 15,0 ; 17,5 \mathrm{mg} . \mathrm{L}^{-1} ; \mathrm{T}=25 \stackrel{\circ}{\mathrm{O}} \mathrm{C}, \mathrm{pH}=$

$6,2)$

O modelo de Langmuir é aplicado em sistemas que aceitam as seguintes hipóteses: As moléculas do adsorbato aderem-se na superfície do adsorvente em locais definidos (sítios); cada sítio ativo apenas acomoda uma molécula do adsorbato. Isso significa que é formada apenas uma monocamada e não há interação entre as moléculas de sítios vizinhos.

A isoterma de Freundlich, geralmente, descreve uma adsorção reversível e não ideal, sendo não restrita a formação de monocamada. Este modelo empírico pode ser aplicado em adsorção multicamada com distribuição não uniforme do calor de adsorção e afinidades sobre uma superfície heterogênea. ${ }^{40}$

As expressões matemáticas para modelos de isotermas de Langmuir são ilustradas na Tabela 7. ${ }^{40-43}$

Tabela 7. Modelos para isoterma de Langmuir

\begin{tabular}{ccc}
\hline Forma não linear & Forma linear & Representação gráfica \\
\hline & $\frac{\mathrm{C}_{\mathrm{e}}}{\mathrm{q}_{\mathrm{e}}}=\frac{1}{\mathrm{k}_{\mathrm{l}} \mathrm{q}_{\mathrm{m}}}+\frac{\mathrm{C}_{\mathrm{e}}}{\mathrm{q}_{\mathrm{m}}}$ & $\frac{\mathrm{C}_{\mathrm{e}}}{\mathrm{q}_{\mathrm{e}}} \mathrm{vs}_{\mathrm{e}}$ \\
$\mathrm{q}_{\mathrm{e}}=\frac{\mathrm{q}_{\mathrm{m}} \mathrm{k}_{\mathrm{l}} \mathrm{C}_{\mathrm{e}}}{1+\mathrm{k}_{\mathrm{l}} \mathrm{C}_{\mathrm{e}}}$ & $\frac{1}{\mathrm{q}_{\mathrm{e}}}=\frac{1}{\mathrm{q}_{\mathrm{m}}}+\frac{1}{\mathrm{k}_{\mathrm{l}} \mathrm{q}_{\mathrm{m}} \mathrm{C}_{\mathrm{e}}}$ & $\frac{1}{\mathrm{q}_{\mathrm{e}}} \mathrm{vs} \frac{1}{\mathrm{C}_{\mathrm{e}}}$ \\
& $\mathrm{q}_{\mathrm{e}}=\mathrm{q}_{\mathrm{m}}-\frac{\mathrm{q}_{\mathrm{e}}}{\mathrm{k}_{\mathrm{l}} \mathrm{C}_{\mathrm{e}}}$ & $\mathrm{q}_{\mathrm{e}} \mathrm{vs} \frac{\mathrm{q}_{\mathrm{e}}}{\mathrm{k}_{\mathrm{l}} \mathrm{C}_{\mathrm{e}}}$ \\
& $\frac{\mathrm{q}_{\mathrm{e}}}{\mathrm{Ce}}=\mathrm{k}_{\mathrm{l}} \mathrm{q}_{\mathrm{m}}-\mathrm{k}_{\mathrm{l}} \mathrm{q}_{\mathrm{e}}$ & $\frac{\mathrm{q}_{\mathrm{e}}}{\mathrm{C}_{\mathrm{e}}} \mathrm{vs} \mathrm{\textrm {q } _ { \mathrm { e } }}$ \\
\hline
\end{tabular}


Onde, $\mathrm{q}_{\mathrm{e}}=$ Quantidade adsorvida na partícula no equilíbrio ( $\left.\mathrm{mg} \mathrm{g}^{-1}\right) ; \mathrm{q}_{\mathrm{m}}=$ Capacidade máxima de adsorção, relacionada à cobertura de uma monocamada $\left(\mathrm{mg} \mathrm{g}^{-1}\right) ; \mathrm{k}_{1}$ = Grau de afinidade, constante de equilíbrio

Tabela 8. Fator de separação $\left(R_{L}\right)$ de adsorção $\left(\mathrm{L} \mathrm{g}^{-1}\right) ; \mathrm{C}_{\mathrm{e}}=$ Concentração na fase líquida no equilíbrio $\left(\mathrm{mg} \mathrm{L}^{-1}\right)$.

Os parâmetros de Langmuir podem ser expressos pelo fator de separação adimensional, $R_{L}$ que permite avaliar a forma da isoterma (Tabela 8).

\begin{tabular}{ccc}
\hline Equação & Fator de separação $\left(\mathbf{R}_{\mathrm{L}}\right)$ & Tipo de Isoterma \\
\hline $\mathrm{R}_{\mathrm{L}}>1$ & Desfavorável \\
$\mathrm{R}_{\mathrm{L}}=\frac{1}{\left(1+\mathrm{k}_{\mathrm{l}} \mathrm{C}_{0}\right)}$ & $\mathrm{R}_{\mathrm{L}}=1$ & Linear \\
& $0<\mathrm{R}_{\mathrm{L}}<1$ & Favorável \\
& $\mathrm{R}_{\mathrm{L}}=0$ & Irreversível \\
\hline
\end{tabular}

Onde, $k_{1}=$ Grau de afinidade da inicial da fase fluida. Na Tabela 9 verifica-se o monocamada de Langmuir; $C_{0}=$ concentração modelo para a isoterma de Freundlich. ${ }^{40-43}$

Tabela 9. Modelos para isoterma de Freundlich

\begin{tabular}{ccc}
\hline Forma não linear & Forma linear & Representação gráfica \\
\hline $\mathrm{q}_{\mathrm{e}}=\mathrm{K}_{\mathrm{f}} \mathrm{C}_{\mathrm{e}}{ }^{1 / \mathrm{n}}$ & $\log \left(\mathrm{q}_{\mathrm{e}}\right)=\log \left(\mathrm{K}_{\mathrm{f}}\right)+\frac{1}{\mathrm{n}} \log \left(\mathrm{C}_{\mathrm{e}}\right)$ & $\log \left(\mathrm{q}_{\mathrm{e}}\right)$ vs $\log \left(\mathrm{C}_{\mathrm{e}}\right)$ \\
\hline
\end{tabular}

Onde, $\mathrm{q}_{\mathrm{e}}=$ Concentração de equilíbrio do sólido $\left(\mathrm{mg} \mathrm{g} \mathrm{g}^{-1}\right) ; \mathrm{C}_{\mathrm{e}}=$ Concentração de equilíbrio do líquido $\left(\mathrm{mg} \mathrm{L}^{-1}\right) ; \mathrm{K}_{\mathrm{f}}$ e $1 / \mathrm{n}=$ Constantes de Freundlich.

Os resultados para o modelo de Langmuir demonstraram que o equilíbrio é bem descrito por este modelo, devido ao coeficiente de correlação ser 0,9591 (Tabela 10).

Tabela 10. Parâmetros físico-químicos de adsorção obtidos a partir do ajuste ao modelo de Langmuir para o adsorbato de azul de metileno a 25 드, em biocarvão

\begin{tabular}{cccccc}
\hline \multirow{2}{*}{ Adsorvente } & \multirow{2}{*}{ Adsorbato } & \multicolumn{4}{c}{ Isoterma de Langmuir } \\
\hline \multirow{2}{*}{ Carvão pirolítico } & \multirow{2}{*}{ Azul de Metileno } & $\left.54 \mathbf{m g ~ g}^{-1}\right)$ & $\mathbf{K}_{\mathbf{l}}\left(\mathbf{L ~ m g} \mathbf{~ m}^{-1}\right)$ & $\mathbf{R}^{\mathbf{2}}$ & $\mathbf{R}_{\mathbf{L}}$ \\
& & 54 & 1,65 & 0,9591 & 0,0572 \\
\hline
\end{tabular}

$\mathrm{O}$ valor de qm, que mede à capacidade máxima de adsorção de um adsorbato em um adsorvente, foi de $54,64 \mathrm{mg} \mathrm{g}^{-1}$ para o adsorbato azul de metileno no adsorvente carvão pirolítico. O fator de separação (RL) foi de 0,0572, mostrando que a adsorção foi favorável $(0<R L<1)$. 
Na Tabela 11 observam-se os parâmetros físico-químicos de adsorção obtidos a partir do ajuste ao modelo de Freundlich para o adsorbato azul de metileno. Os resultados demonstraram que o equilíbrio foi bem descrito pela isoterma de Freundlich, devido ao coeficiente de correlação ser 0,9978 . Este modelo apresentou uma correlação melhor em comparação com a isoterma de Langmuir. $O$ valor de $K_{f}$ foi de 59,69 $\mathrm{mg} \mathrm{g}^{-1}$ para o adsorbato azul de metileno no adsorvente biocarvão. Este mede a capacidade máxima de adsorção de um adsorbato em um adsorvente. A constante $1 / \mathrm{n}$ descreve a intensidade de adsorção, sendo favorável na faixa de 0 a 1 . Neste caso, o valor de $1 / n$ foi de 0,91 . Esses dois parâmetros obtidos são importantes para determinar a capacidade de adsorção de diferentes adsorventes. Como $1 / n<1$, existe uma interação entre 0 adsorvente e o adsorbato, isto é, o biocarvão adsorve o azul de metileno, em proporções significativas. Esta adsorção adapta-se melhor ao modelo de Freundlich quando comparado com o modelo de Langmuir.

Tabela 11. Parâmetros físico-químicos de adsorção obtidos a partir do ajuste ao modelo de Freundlich para o adsorbato de azul de metileno a $25 \stackrel{\circ}{\circ}$

\begin{tabular}{ccccc}
\hline \multirow{2}{*}{ Adsorvente } & Adsorbato & & Isoterma de Freundlich & \\
& & $\mathbf{1 / n}$ & $\mathbf{K}_{\mathrm{f}}\left(\mathbf{m g} \cdot \mathbf{g}^{-\mathbf{1}}\left(\mathbf{L ~ m g}^{-1}\right)^{\mathbf{1 / n}}\right)$ & $\mathbf{R}^{\mathbf{2}}$ \\
\hline Carvão pirolítico & Azul de Metileno & 0,91 & 59,69 & 0,9978 \\
\hline
\end{tabular}

\subsection{Cinética de Adsorção}

A Figura 10 apresenta a cinética de adsorção de azul de metileno pelo biocarvão.
Observa-se que após $30 \mathrm{~min}$ houve uma remoção média de $98 \%$ para solução aquosa de azul de metileno a $10 \mathrm{mg} \mathrm{L}^{-1}$.

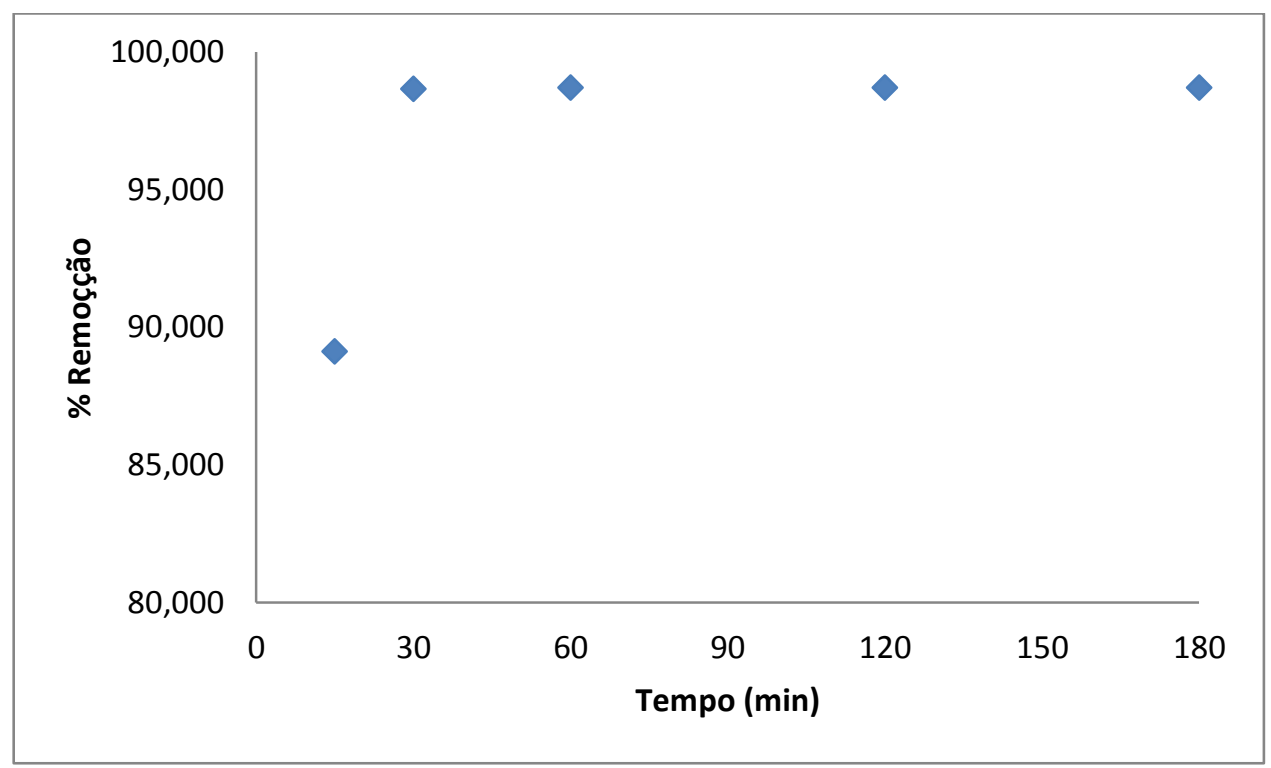

Figura 10. Cinética de adsorção de azul de metileno no biocarvão (10 mg de biocarvão; $10 \mathrm{~mL}$ de solução do corante; $T=25 \stackrel{\circ}{ } \mathrm{C} ; \mathrm{pH}=6,2$ ) 
A cinética do processo de adsorção do corante azul de metileno pelo biocarvão foi investigada através dos modelos de pseudoprimeira ordem e pseudo-segunda ordem.

A equação cinética de pseudo 1a ordem de Lagergren baseada na capacidade de adsorção do sólido, descrita na Tabela 12, representa o modelo cinético de pseudo 1ạ ordem. Para se obter a forma linearizada, a equação é integrada nas seguintes condições: $\mathrm{t}=0, \mathrm{t}=\mathrm{t}, \mathrm{q}_{\mathrm{t}}=0 \mathrm{e} \mathrm{q}_{\mathrm{t}}=\mathrm{q}_{\mathrm{t}}$. A constante de velocidade $k_{1}$ pode ser obtida do declive da reta do gráfico de $\log \left(q_{e}-q_{t}\right)$ vs $t^{40,44}$

Tabela 12. Modelo pseudo 1a ordem

\begin{tabular}{lll}
\hline Equação & Forma linear & Representação gráfica \\
\hline$\frac{d q_{t}}{d t}=k_{1}\left(q_{e}-q_{t}\right)$ & $\log \left(q_{e}-q_{t}\right)=\log \left(q_{e}\right)-\left(\frac{k_{1}}{2,303}\right) t$ & $\log \left(q_{e}-q_{t}\right)$ vs $t$ \\
\hline
\end{tabular}

Em que, $k_{1}=$ constante cinética de 1 a ordem $\left(\mathrm{min}^{-1}\right) ; \mathrm{q}_{\mathrm{e}}=$ quantidade de adsorbato adsorvido no equilíbrio $\left(\mathrm{mg} \mathrm{g}^{-1}\right) ; \mathrm{q}_{\mathrm{t}}=$ quantidade de adsorbato adsorvido pela superfície no tempo $\mathrm{t}\left(\mathrm{mg} \mathrm{g}^{-1}\right)$.

A partir da quantidade de azul de metileno adsorvida no equilíbrio $\left(q_{\mathrm{e}}\right)$ e da quantidade de azul de metileno adsorvida no tempo " $\mathrm{t}$ " $\left(\mathrm{q}_{\mathrm{t}}\right)$, obtidos no ensaio da cinética de adsorção, foi possível avaliar o ajuste dos pontos no modelo de pseudo-primeira ordem.

Os valores dos coeficientes de correlação obtidos para a concentração inicial de $10 \mathrm{mg}$ $\mathrm{L}^{-1}$ de azul de metileno a 25 으 foi de 0,8952 , o que demonstra que não houve um bom ajuste dos dados utilizando este modelo, como demonstrado na Tabela 13.

Tabela 13. Parâmetros do modelo de pseudo-primeira ordem

\begin{tabular}{cccc}
\hline $\begin{array}{c}\mathbf{q}_{\mathrm{e} \text { (experimental) }} \\
\left(\mathbf{m g} \cdot \mathbf{g}^{-\mathbf{1}}\right)\end{array}$ & $\begin{array}{c}\mathbf{q}_{\mathrm{e}(\text { teórico) }} \\
\left(\mathbf{m g} \cdot \mathbf{g}^{-1}\right)\end{array}$ & $\begin{array}{c}\mathbf{K}_{\mathbf{1}} \\
\left(\mathbf{m i n}^{-1}\right)\end{array}$ & $\mathbf{R}^{\mathbf{2}}$ \\
\hline 9,8655 & 5,6480 & 0,26853 & 0,8952 \\
\hline
\end{tabular}

A equação cinética de pseudo 2a ordem também se baseia na capacidade de adsorção do sólido, como descrito na Tabela 14. Para se obter a forma linearizada, a equação é integrada nas seguintes condições: $t=0, t=$ $\mathrm{t}, \mathrm{q}_{\mathrm{t}}=0$ e $\mathrm{q}_{\mathrm{t}}=\mathrm{q}_{\mathrm{t}}$. A constante de velocidade $\mathrm{k}_{2}$ pode ser obtida do declive da reta do gráfico de $t / q_{t} v_{s} t^{40,44}$

Tabela 14. Modelo pseudo 2a ordem

\begin{tabular}{ccc}
\hline Equação & Forma linear & Representação gráfica \\
\hline$\frac{\mathrm{dq}}{\mathrm{dt}}=k_{2}\left(q_{e}-q_{t}\right)^{2}$ & $\frac{\mathrm{t}}{\mathrm{q}_{\mathrm{t}}}=\frac{1}{k_{2} q_{e}{ }^{2}}+\frac{1}{q_{e}} t$ & $\frac{\mathrm{t}}{\mathrm{q}_{\mathrm{t}}} v s t$ \\
$\frac{\mathrm{t}}{\mathrm{q}_{\mathrm{t}}}=\frac{1}{h}+\frac{1}{q_{e}} t$ & \\
\hline
\end{tabular}


Em que, $k_{2}$ - constante cinética de $2^{a}$ ordem ( $\left.\mathrm{g} \mathrm{mg}^{-1} \mathrm{~min}^{-1}\right) ; \mathrm{q}_{\mathrm{e}}$ - quantidade de adsorbato adsorvido no equilíbrio $\left(\mathrm{mg} \mathrm{g}^{-1}\right) ; q_{t}$ - quantidade de adsorbato adsorvido pela superfície no tempo $\mathrm{t}\left(\mathrm{mg} \mathrm{g}^{-1}\right) ; \mathrm{h}$ - velocidade inicial de adsorção $\left(\mathrm{mg} \mathrm{g}^{-1} \mathrm{~min}^{-1}\right)$.

A partir da linearização do modelo é possível obter a constante de velocidade de pseudo-segunda ordem $\left(k_{2}\right)$ através do coeficiente linear, e o valor da quantidade adsorvida no equilíbrio (qe) através do coeficiente angular, sendo que este último pode ser comparado ao valor obtido experimentalmente, conforme mostrado na Tabela 15.
Analisando os dados foi possível observar que o coeficiente de correlação obtido para este modelo cinético foi de 0,9981 , indicando claramente um processo de pseudo-segunda ordem. O valor da quantidade adsorvida no equilíbrio $\left(\mathrm{q}_{\mathrm{e}}\right)$ teórico apresenta um valor muito próximo ao obtido experimentalmente, o que ratifica a validade do modelo. Também nota-se que a velocidade inicial de adsorção (h) foi de 9,1575 $\mathrm{mg} \mathrm{g}^{-1} \mathrm{~min}^{-1}$, indicando que $\mathrm{o}$ processo de adsorção é extremamente rápido.

Tabela 15. Parâmetros do modelo de pseudo-segunda ordem

\begin{tabular}{|c|c|c|c|c|}
\hline $\begin{array}{c}q_{e} \text { (experimental) } \\
\left(\mathrm{mg} \mathrm{g}^{-1}\right)\end{array}$ & $\begin{array}{l}q_{\text {e(teórico) }} \\
\left(\mathrm{mg} \mathrm{g}^{-1}\right)\end{array}$ & $\begin{array}{c}\mathrm{K}_{2} \\
\left(\mathrm{~g} \mathrm{mg}^{-1} \mathrm{~min}^{-1}\right)\end{array}$ & $\begin{array}{c}\mathrm{h} \\
\left(\mathrm{mg} \mathrm{g}^{-1} \min ^{-1}\right)\end{array}$ & $\mathrm{R}^{2}$ \\
\hline 9,8655 & 10,3412 & 0,26853 & 9,1575 & 0,9981 \\
\hline
\end{tabular}

\section{Considerações Finais}

O processo de pirólise é uma importante ferramenta na destinação adequada de resíduos agrícolas e da agroindústria. $\mathrm{O}$ processo pirólise lenta para o tratamento da torta de filtro gerou um rendimento da fração sólida (biocarvão) bastante elevado (68\%). O rendimento da fração gasosa (17\%) também foi bastante promissor e pode suprir as necessidades do processo no aquecimento do reator de pirólise. A fração aquosa (11 \%) pode ser utilizada como fertilizante no plantio da cana de açúcar e o pouco óleo (4 $\%)$ obtido pode voltar ao processo de pirólise como biocombustível.

O biocarvão é um produto com alto valor agregado, e mostrou-se um excelente adsorvente mesoporoso, com rendimento de remoção de $98 \%$, em 30 min, do corante azul de metileno a partir de soluções aquosas, apresentando, assim, um excelente potencial para ser utilizado em processos de adsorção no tratamento efluentes. A composição química do biocarvão indica que este pode ser usado também para adubação orgânica, devido à presença da quantidade adequada de $\mathrm{N}, \mathrm{P}, \mathrm{K}$ e baixo teor de metais. A avaliação do poder calorífico superior do biocarvão e do gás pirolítico mostrou-se pouco eficaz para a utilização dos mesmos como combustíveis alternativos, com uma estimativa de gerar 5,97 MJ e 0,69 MJ, a partir de $1 \mathrm{~kg}$ de torta de filtro seca, respectivamente.

\section{Referências Bibliográficas}

${ }^{1}$ Mahler, C. F.; Schueler, A. S.; Soares, E.; Alves, I. R. F. S.; Almeida, J. R.; Andrade, J. C. M.; Rosa, L. P.; Oliveira, L. B.; Guiõa JR, R.; Fonseca, Z. S. Lixo urbano: o que você precisa saber sobre o assunto. Revan: Rio de Janeiro, 2012.

${ }^{2}$ Bahng, M. K.; Mukarakate, C.; Robichaud, D. J.; Nimlos, M. R. Current technologies for 
analysis of biomass thermochemical processing: a review. Analytica Chimica Acta 2009, 651, 117. [CrossRef] [PubMed]

${ }^{3}$ Silveira, I. C. T.; Rosa, D.; Monteggia, L. O.; Romeiro, G. A.; Bayer, E.; Kutubuddin, M. Low temperature conversion of sludge and shavings from leather industry. Water Science and Technology 2002, 46, 277. [PubMed]

${ }^{4}$ Demirbas, M. F.; Balat, M.; Balat, H. Biowastes-to-biofuels. Energy Conversion and Management 2011, 52, 1815. [CrossRef]

${ }^{5}$ Silva, R. V. S.; Casilli, A.; Sampaio, A. L.; Ávila, B. M. F.; Veloso, M. C. C.; Azevedo, D. A.; Romeiro, G. A. The analytical characterization of castor seed cake pyrolysis bio-oils by using comprehensive GC coupled to time of flight mass spectrometry. Journal of Analytical and Applied Pyrolysis 2014, 106, 152. [CrossRef]

${ }^{6}$ Figueiredo, M. K.-K.; Romeiro, G. A.; Silva, R. V. S.; Pinto, P. A.; Damasceno, R. N.; D`Avila, L. A.; Franco, A. P. Pyrolysis oil from the fruit and cake of Jatropha curcas produced using a low temperature conversion (LTC) process: analysis of a pyrolysis oil-diesel blend. Energy and Power Engineering 2011, 3, 332. [CrossRef]

${ }^{7}$ Yoder, J.; Galinato, S.; Granatstein, D.; Garcia, M. Economic tradeoff between biochar and bio-oil production via pyrolysis. Biomass and Bioenergy 2011, 35, 1851. [CrossRef]

${ }^{8}$ Ahmad, M.; Rajapaksha, A. U.; Lim, J. E.; Zhang, M.; Bolan, N.; Mohan, D.; Vithanage, M.; Lee, S. S.; Ok, Y. S. Biochar as a sorbent for contaminant management in soil and water: a review. Chemosphere 2014, 99, 19. [CrossRef] [PubMed]

${ }^{9}$ Mohan, D.; Sarswat, A.; Ok, Y. S.; Pittman, C. $U$. Organic and inorganic contaminants removal from water with biochar, a renewable, low cost and sustainable adsorbent - a critical review. Bioresource technology 2014, 160, 191. [CrossRef] [PubMed]

${ }^{10}$ Mathew, S.; Zakaria, Z. A.; Musa, N. F. Antioxidant property and chemical profile of pyroligneous acid from pineapple plant waste biomass. Process Biochemistry 2015, 50, 1985. [CrossRef]
${ }^{11}$ Souza, J. B. G.; Ré-Poppi, N.; Raposo, J. L. Characterization of pyroligneous acid used in agriculture by gas chromatography-mass spectrometry. Journal of the Brazilian Chemical Society 2012, 23, 610. [CrossRef]

${ }^{12}$ Fravet, P. R. F.; Soares, R. A. B.; Lana, R. M. Q.; Lana, Â. M. Q.; Korndörfer, G. H. Efeito de doses de torta sobre a produtividade e qualidade tecnológica da soqueira de canade-açúcar. Ciência e Agrotecnologia 2010, 34, 618. [CrossRef]

${ }^{13}$ CONAB Acompanhamento da Safra Brasileira da Cana-de-açúcar - Safra 2017/2018. Companhia Nacional de Abastecimento 2017, 4, 1. [Link]

${ }^{14}$ Santos, D. H.; Silva, M. D. A.; Tiritan, C. S.; Foloni, J. S. S.; Echer, F. R. Qualidade tecnológica da cana-de-açúcar sob adubação com torta de filtro enriquecida com fosfato solúvel. Revista Brasileira de Engenharia Agrícola e Ambiental 2011, 15, 443. [Link]

${ }^{15}$ Lima, C. C.; Mendonça, E. S.; Silva, I. R.; Silva, L. H. M.; Roig, A. Caracterização química de resíduos da produção de biodiesel compostados com adição mineral. Engenharia Agrícola e Ambiental 2009, 13, 334. [Link]

${ }^{16}$ Chacón, E. A. V; Mendonça, E. S.; Silva, R. R.; Lima, P. C.; Cantarutti, R. B. Decomposição de fontes orgânicas e mineralização de formas de nitrogênio e fósforo. Revista Ceres 2011, 58, 373. [Link]

${ }^{17}$ Tsai, W. T.; Chen, H. P.; Lai, C. W.; Hsien, K. J.; Lee, M. S.; Yang, J. M. Preparation of adsorbents from sugarcane manufacturing by-product filter-mud by thermal activation. Journal of Analytical and Applied Pyrolysis 2003, 70, 399. [CrossRef]

${ }^{18}$ Blagodatskaya, E.; Kuzyakov, Y. Mechanisms of real and apparent priming effects and their dependence on soil microbial biomass and community structure: critical review. Biology and Fertility of Soils 2008, 45, 115. [CrossRef]

${ }^{19}$ Boechat, C. L.; Santos, J. A. G.; Accioly, A. M. D. A.; Bomfim, M. R.; Santos, A. C. Dos Industrial and urban organic wastes increase soil microbial activity and biomass. Revista Brasileira de Ciência do Solo 2012, 36, 1629. [CrossRef] 
${ }^{20}$ Mohan, D.; Pittman, C. U.; Steele, P. H. Pyrolysis of wood/biomass for bio-oil: A critical review. Energy and Fuels 2006, 20, 848. [CrossRef] [PubMed]

${ }^{21}$ Goyal, H. B.; Seal, D.; Saxena, R. C. Bio-fuels from thermochemical conversion of renewable resources: A review. Renewable and Sustainable Energy Reviews 2008, 12, 504. [CrossRef] [PubMed]

${ }^{22}$ Bayer, E.; Kutubuddin, M. Research in thermochemical biomass conversion Springer Netherlands: Dordrecht, 1988.

2323 Vieira, G. E. G.; Romeiro, G. A.; Sella, S.

M.; Damasceno, R. N.; Pereira, R. G. Low temperature conversion (LTC)--an alternative method to treat sludge generated in an industrial wastewater treatment station-batch and continuous process comparison. Bioresource technology 2009, 100, 1544. [CrossRef] [PubMed]

${ }^{24}$ Romeiro, G. A.; Salgado, E. C.; Silva, R. V. S.; Figueiredo, M. K.-K.; Pinto, P. A.; Damasceno, R. N. A study of pyrolysis oil from soluble coffee ground using low temperature conversion (LTC) process. Journal of Analytical and Applied Pyrolysis 2012, 93, 47. [CrossRef]

${ }^{25}$ Bernardino, C. A. R.; Mahler, C. F.; Veloso, M. C. C.; Romeiro, G. A. Preparation of Biochar from Sugarcane By-product Filter Mud by Slow Pyrolysis and Its Use Like Adsorbent. Waste and Biomass Valorization 2017, 8, 2511. [CrossRef]

${ }^{26}$ Bridgwater, A. V Fast pyrolysis of biomass: a handbook, 3a. ed, CPL Press: Newbury, 2005.

${ }^{27}$ Meier, D.; Faix, O. State of the art of applied fast pyrolysis of lignocellulosic materials - a review. Bioresiurce Technology 1999, 68, 71. [CrossRef]

${ }^{28}$ Agência Nacional de Energia Elétrica Atlas de energia elétrica do Brasil, 2a. ed, Brasília, 2005.

${ }^{29}$ CONAB Companhia Brasileira de Abastecimento. Cana-de-açucar: safra 2013 / 2014 Brasília, 2014. [Link]

${ }^{30}$ Benites, V. M.; Teixeira, W. G.; Rezende, M. E.; Pimenta, A. S. Em As Terras Pretas de Índio da Amazônia: sua caracterização e uso deste conhecimento na criação de novas áreas Embrapa Amazônia Ocidental, 2009, pág 285. [Link]

${ }^{31}$ DECHEN, A. R.; NACHTIGALL, G. R. Em Fertilidade do Solo Sociedade Brasileira de Ciência do Solo: Viçosa, 2007, cap 3.

32 Mendes, A. M. S. Introdução a fertilidade do solo. Embrapa Semi-Árido 2007, 1. [Link]

33 Oliveira, D. L. Solos uma questão de sustentabilidade. Gestão \& Tecnologia 2010, 30. [Link]

${ }^{34}$ Yadav, A.; Ansari, K. B.; Simha, P.; Gaikar, V. G.; Pandit, A. B. Vacuum pyrolysed biochar for soil amendment. Resource-Efficient Technologies 2016, 2, S177. [CrossRef]

${ }^{35}$ Hameed, B. H.; Ahmad, A. L.; Latiff, K. N. A. Adsorption of basic dye (methylene blue) onto activated carbon prepared from rattan sawdust. Dyes and Pigments 2007, 75, 143. [CrossRef]

${ }^{36}$ Bhatnagar, A.; Sillanpää, M. Utilization of agro-industrial and municipal waste materials as potential adsorbents for water treatmenta review. Chemical Engineering Journal 2010, 157, 277. [CrossRef]

${ }^{37}$ Ahmedna, M.; Marshall, W. E.; Rao, R. M. Production of granular activated carbons from select agricultural by-products and evaluation of their physical, chemical and adsorption properties. Bioresource Technology 2000, 71, 113. [CrossRef]

${ }^{38}$ Lu, Q.; Wang, Z.; Dong, C.; Zhang, Z.; Zhang, Y.; Yang, Y.; Zhu, X. Selective fast pyrolysis of biomass impregnated with $\mathrm{ZnCl}$ : Furfural production together with acetic acid and activated carbon as by-products. Journal of Analytical and Applied Pyrolysis 2011, 91, 273. [CrossRef]

${ }^{39}$ Wang, Z.; Wang, F.; Cao, J.; Wang, J. Pyrolysis of pine wood in a slowly heating fixed-bed reactor: potassium carbonate versus calcium hydroxide as a catalyst. Fuel Processing Technology 2010, 91, 942. [CrossRef]

${ }^{40}$ Ahmed, M. J.; Dhedan, S. K. Equilibrium isotherms and kinetics modeling of methylene blue adsorption on agricultural wastes-based activated carbons. Fluid Phase Equilibria 2012, 317, 9. [CrossRef]

${ }^{41}$ Mezohegyi, G.; van der Zee, F. P.; Font, J.; Fortuny, A.; Fabregat, A. Towards advanced 
aqueous dye removal processes: a short review on the versatile role of activated carbon. Journal of environmental management 2012, 102, 148. [CrossRef] [PubMed]

${ }^{42}$ Guedidi, H.; Reinert, L.; Lévêque, J.-M.; Soneda, Y.; Bellakhal, N.; Duclaux, L. The effects of the surface oxidation of activated carbon, the solution $\mathrm{pH}$ and the temperature on adsorption of ibuprofen. Carbon 2013, 54, 432. [CrossRef]

${ }^{43}$ Malamis, S.; Katsou, E. A review on zinc and nickel adsorption on natural and modified zeolite, bentonite and vermiculite: examination of process parameters, kinetics and isotherms. Journal of hazardous materials 2013, 252-253, 428. [CrossRef] [PubMed]

${ }^{44}$ Baccar, R.; Blánquez, P.; Bouzid, J.; Feki, M.; Attiya, H.; Sarrà, M. Modeling of adsorption isotherms and kinetics of a tannery dye onto an activated carbon prepared from an agricultural by-product. Fuel Processing Technology 2013, 106, 408. [CrossRef] 